\title{
Why you shouldn't always follow the crowd
}

\author{
The Perfect Swarm: The Science of \\ Complexity in Everyday Life \\ by Len Fisher \\ Basic Books: 2009. 288 pp. \$29, £13.99
}

A school of fish dives and darts to avoid a predator. The motions of each fish appear chaotic, yet as a group they are effective the school seems intelligent. Our instinct is to look to individual behaviours and to try to assign a leader, yet biologists have shown that collectives can act purposefully without direction. Group skills emerge from the web of interactions between individuals. Similarly, the shininess of gold foil results from the electronic interactions of many atoms; no single atom can be said to be shiny.

A peculiar rift must be confronted in going from the individual to the collective, as science writer Len Fisher explains in his book. The Perfect Swarm focuses on swarm intelligence - the emergence of purposeful, effective and flexibly adaptive group behaviour from interactions between members following simple rules. Fisher explores how this phenomenon unites the behaviour of ants, fish, birds and locusts, and how it links to all areas of complexity science, from neurobiology to ecology. He also embraces the tough challenge

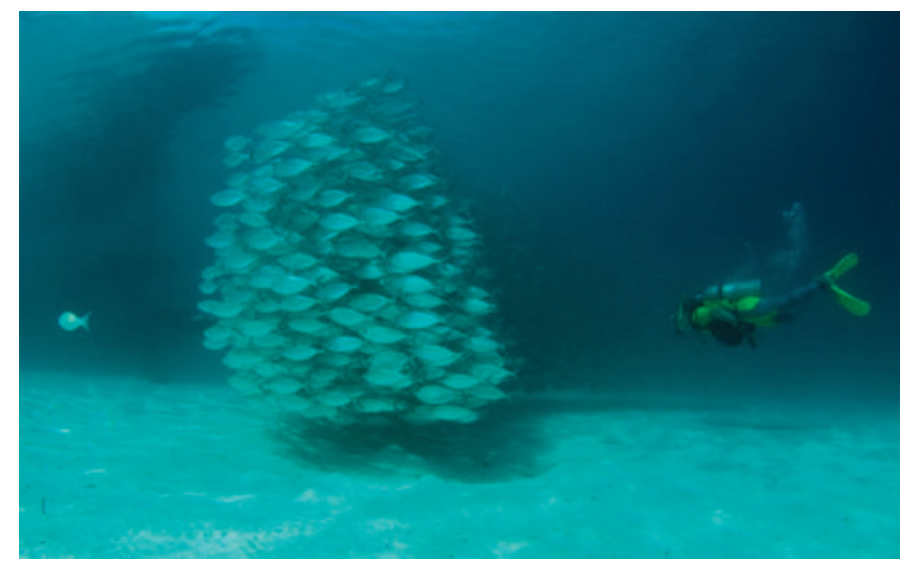

To survive in a fleeing crowd, you should make your own way $40 \%$ of the time. of translating the science into practical lessons for everyday life.

Fisher argues that swarm intelligence lies at the heart of human social capability. Our skill in acquiring ideas and technologies from others, now especially through the Internet, means that anything learned by one person can benefit all. Fisher rightly acknowledges the potential dysfunctions of group dynamics. One example is groupthink - the narrowing of vision and closure to competing ideas that is common to committees.

Swarm dynamics touch on many areas of complexity science, from the study of networks to the discovery of meaningful patterns in masses of data. Fisher describes how abstract mathematical entities that mimic swarms are being used to find features in complex data sets, such as images or financial market fluctuations. Much as a flock of birds reacts when encountering a sharp cliff face, the mathematical swarms signal potentially important discontinuities.

Based on a profusion of examples, mainly biological, Fisher draws up rules for living in a complex world. Few books have attempted this; one exception is Harnessing Complexity by Robert Axelrod and Michael Cohen (Free Press, 2000). Fisher explores rules for business, for social networking and for finding the right balance between perfect solutions versus crude but effective rules of thumb. He includes surprising advice, based on computer simulations of crowd dynamics, for surviving in a crowd that is fleeing catastrophe. To benefit from others' possible knowledge of the best route, but to avoid following the herd into a dead end, Fisher suggests that you should "follow the crowd 60 per cent of the time, and spend the other 40 per cent searching out escape routes on your own".

By focussing wholly on the science of complexity without using narrative ploys to disguise it, Fisher covers a vast subject quickly in a compact book. The Perfect Swarm is a valuable contribution.

Mark Buchanan is a writer based in the United Kingdom and author of The Social Atom.

e-mail:buchanan.mark@gmail.com

\section{Autism and animal insight}

Temple Grandin

Directed by Mick Jackson

US broadcast by HBO on 6 February 2010

"I'm not like other people," declares actress Claire Danes as animal-behaviour expert Temple Grandin in director Mick Jackson's latest film. Unable to speak until age four, Grandin was diagnosed as autistic. Yet she earned a PhD, became an associate professor of animal science at Colorado State University in Fort Collins and has written best-selling books and articles on the behaviour and welfare of food animals.

Danes captures brilliantly Grandin's personality through details such as her robotic speech and stilted gait. The film gives her view of the world through clever cutting to everyday details, such as a ceiling fan or automatic sliding doors, which spook her in a way that she believes is characteristic of animals' perception. The film reveals that more than half of US livestockhandling facilities have been built to Grandin's designs. But it goes too far by presenting her as the originator of an entire field of science.

The film reifies the idea that people with autism have special insight, yet there is no scientific evidence for this. Grandin's ability to 'see' as animals do, to experience the anxiety of being herded, is made concrete and compelling. However, the brains of people with autism are no more like the brains of cattle than those of any neurotypical person, and there is no evidence that animals process sensory information as humans with autism do. Informed debate regarding animal-production practices cannot take place when some parties claim to have privileged, and thus irrefutable, evidence.

By romanticizing Grandin's autistic empathy, the film avoids answering how much empathy is possible in a US animal-production system that slaughters 10 billion animals a year. The film begs the wider question of why anxiety in cattle matters. Instead it relies on the cursory economic justification that better animal treatment saves money by avoiding stress-related injuries, and appeals for personal responsibility to respect an animal when we take its life.

Grandin is exceptional, but it is far from clear what that implies for other individuals with autism-spectrum disorders. Jackson's film brings to life her struggles to fight real prejudice. Unfortunately, it does not convey that it takes more than empathy to understand animal behaviour - it takes science.

Wes Jamison is associate professor of communication at Palm Beach Atlantic University in West Palm Beach, Florida, USA. Clive Wynne is associate professor of psychology at the University of Florida in Gainesville, Florida, USA. e-mail:wynne@ufl.edu 